\title{
MORFO-ANATOMIA DE ESPÉCIES DE BLASTOCAULON RUHLAND (ERIOCAULACEAE)
}

\author{
Vera Lucia Scatena' \\ Vanessa de Aquino Cardoso' \\ Ana Maria Giulietti
}

Recebido em 21/08/1998. Aceito em 02/02/1999

\begin{abstract}
RESUMO - (Morfo-anatomia de espécies de Blastocaulon Ruhland (Eriocaulaceae). Estudou-se a morfo-anatomia das raízes, caules, escapos e folhas de Blastocaulon albidum, B. prostratum e B. scirpeum, que ocorrem nos campos rupestres de Minas Gerais, Brasil. Verificou-se que as espécies apresentam raízes muito finas com epiderme unisseriada, duastrês camadas de células do parênquima cortical e tecidos vasculares com poucos elementos. Os caules em B. albidum e B. prostratum são aéreos, prostrados, ramificados, enquanto em B. scirpetum alguns indivíduos apresentam rizoma ou caules muito curtos. Constituem-se de epiderme, córtex e cilindro vascular. As folhas são delicadas, com células da epiderme com paredes finas, parênquima clorofiliano frouxo e reduzido número de feixes vasculares colaterais. Os escapos são cilíndricos, finos, não formam costelas e possuem apenas quatro feixes vasculares colaterais. As características observadas nessas espécies estudadas são típicas de plantas que ocorrem em locais úmidos e sombreados, ambientes onde é encontrada a maioria das espécies de Blastocaulon e ainda caracterizam anatomicamente o gênero, que se diferencia de Paepalanthus.
\end{abstract}

Palavras-chave - morfologia, anatomia, Blastocaulon

ABSTRACT - (Morpho-anatomy of species of Blastocaulon Ruhland (Eriocaulaceae). The morpho-anatomy of roots. stems, scapes and leaves of Blastocaulon albidum, B. prostratum and B. scirpeum was studied. All species occur in campos rupestres of Minas Gerais, central Brazil. They possess very fine roots with a uniseriate epidermis, two-three layers of parenchymatous cells in the cortex, and a vascular tissue with few elements. The stem of $B$. albidum and $B$. prostratum are aerious and branched while in $B$. scirpeum some individuals have rhizoma or very short stems. They have epidermis. cortex and a vascular cylinder. The leaves are delicate, with thin-walled epidermal cells, loosely aggregated chlorophyll parenchyma and a reduced number of vascular bundles. The scapes are cylindrical, slender, without ribs and only have four collateral vascular bundles. These characteristics which distinguish Blastocaulon from Paepalanthus. are typical of plants growing in damp shady habitats, the environment where most Blastocaulon species are found.

Key words - morphology, anatomy, Blastocaulon

\section{Introdução}

A família Eriocaulaceae possui cerca de 1.200 espécies em dez gêneros, com distribuição pantropical
(Giulietti et al. 1995). O centro de diversidade genética da família está no sudeste do Brasil, nas regiões das montanhas da Cadeia do Espinhaço, em Minas Gerais (Giulietti \& Hensold 1990).

1 Departamento de Botânica, Instituto de Biociências, UNESP, C.Postal 199. CEP 13506-900, Rio Claro, São Paulo, Brasil, Bolsa de Produtividade em Pesquisa, CNPq

Departamento de Ciências Biológicas, Universidade Estadual de Feira de Santana, Km 3, BR 116, Câmpus Universitário. CEP 44031-460. Feira de Santana, BA. Brasil. Bolsa de Produtividade em Pesquisa, CNPq 
O gênero Eriocaulon inclui toda a área de distribuição geográfica da família. Dos gêneros restantes, alguns têm áreas de distribuição mais restritas, como Mesanthemum, restrito à África, Lachnocaulon, só das Américas do Norte e Central, Rondonanthus, exclusivo da Venezuela e Guianas, e Philodice e Blastocaulon, endêmicos de pequenas áreas do Brasil, respectivamente do Mato Grosso, Minas Gerais e Bahia. Os outros gêneros apresentam distribuição mais ampla, como Leiothrix e Tonina, de ocorrência em toda a área neotropical, e Syngonanthus e Paepalanthus com distribuição disjunta na África e América do Sul (Giulietti \& Hensold 1990).

O gênero Blastocaulon inclui apenas cinco espécies, distribuídas em Minas Gerais, principalmente em Diamantina, e na Bahia. O gênero foi proposto por Ruhland (1903) e tem como principal distinção de Paepalanthus as anteras monotecas. Por esta característica, Giulietti (1978a) incluiu Paepalanthus scirpeus Mart. neste gênero, propondo a nova combinação Blastocaulon scirpeum (Mart.) Giul. As espécies do gênero são muito delicadas e geralmente apresentam caule ramificado e ocorrem em sombras de cavernas (Giulietti \& Hensold 1990).

Várias espécies de diferentes gêneros de Eriocaulaceae foram estudadas anatomicamente e suas características têm sido usadas com fins taxonômicos em diferentes níveis hierárquicos, como por exemplo, em Syngonanthus (Scatena \& Menezes 1996a), onde as características anatômicas de folhas e escapos são utilizadas para separar seções; em Leiothrix crassifolia, Scatena \& Giulietti (1996) utilizaram características anatômicas de folhas e escapos para sinonimizar dois táxons nesta espécie; em Paepalanthus subgênero Platycaulon Scatena et al. (1998) mostraram que as características anatômicas de escapos podem ser utilizadas para caracterizar o subgênero e suas distintas seções.

Este trabalho teve como objetivo caracterizar anatomicamente o gênero Blastocaulon, visando subsidiar uma futura caracterização anatômica da família e verificar se, anatomicamente, o gênero pode ser distinto de Paepalanthus.

\section{Material e métodos}

Para a realização deste trabalho foram estudados os seguintes espécimes: Blastocaulon albidum (Gardn.) Ruhland. BRASIL. Minas Gerais: Diamantina, 18/V/1990, caminho para Conselheiro Mata, Arbo et al. 4362 (SPF)*; 31/VIII/ 1981, 6 km de Diamantina, Curralinho, Menezes \& Matos CFCR 1885 (SPF); 14/VII/1984, Giulietti et al. CFCR 4437 (SPF). Blastocaulon prostratum (Koern.) Ruhland; Santo Antonio do Itambé, 21/ II/1982, Hensold 496 (SPF)*; 12/III/95, início da estrada para o Pico do Itambé, Souza et al. 8401 (ESA, SPF). Blastocaulon scirpeum (Koern.) Giul.; Barão de Cocais, 04/IV/1982, Serra do Garimpo, Hensold 767 (SPF)*; Santana do Riacho, 05/VII/ 1978, Serra do Cipó, Giulietti CFSC 5508 (SPF); Serro, 25/V/1978, km 22 da estrada Serro-Datas, Ferreira 7255 (PAMG, SPF). *Os espécimes assinalados com asterisco são aqueles representados nas ilustrações deste trabalho.

O estudo anatômico das raízes, caules, escapos e folhas foi feito em material herborizado obtido de exsicatas do herbário SPF, fervidos em água com glicerina para expansão dos tecidos e posteriormente transferidos para álcool $70 \%$. Os cortes anatômicos foram feitos à mão livre, nas regiões medianas das raízes, caules, escapos e folhas e em toda a extensão do rizoma. Os cortes foram corados com fucsina e azul de astra (Roeser 1962) e montados em gelatina glicerinada entre lâmina e lamínula.

\section{Resultados}

As espécies de Blastocaulon estudadas apresentam hábitos variados. Blastocaulon albidum (Fig. 1) caracteriza-se por apresentar caule aéreo prostrado, ramificado, com folhas reduzidas, lineares, delicadas, que se dispõem ao longo de todo o caule. Nas ramificações do caule, principalmente nas regiões basais e medianas da planta, observamse saídas de raízes adventícias. Os escapos florais saem da porção terminal dos ramos. B. prostratum (Fig. 2) caracteriza-se por apresentar caule aéreo desenvolvido ou mesmo reduzido, com ramificações, com folhas mais longas, lineares, e mais espessas do que as de B. albidum. Também apresenta saídas de raízes adventícias na região de ramificação e escapos terminais. Bem diferente é B. scirpeum (Fig. 3) que se caracteriza por apresentar rizoma reduzido, oblíquo na maioria dos 


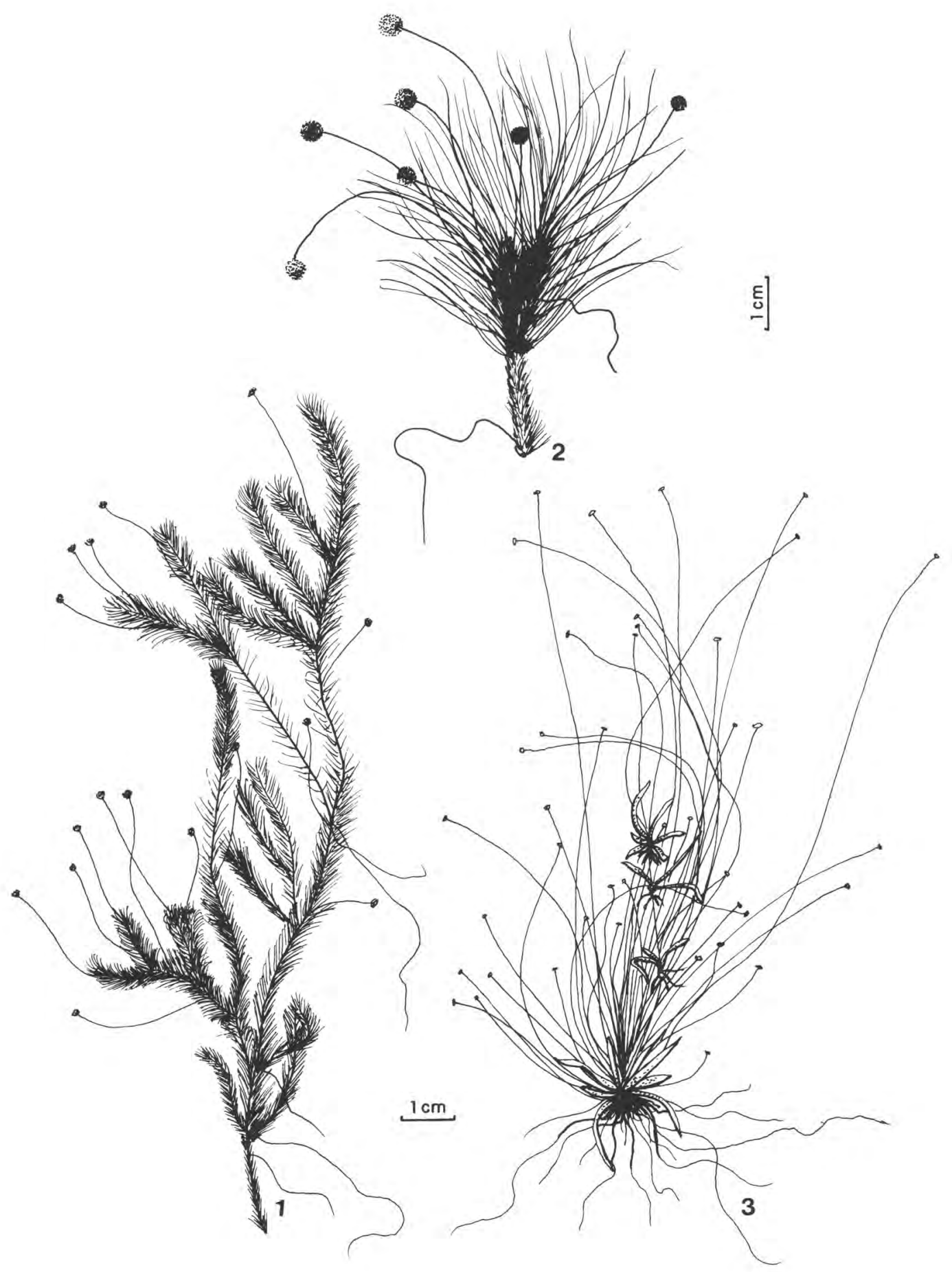

Figuras 1-3. Aspectos morfológicos de Blastocaulon: 1. B. albidum; 2. B. prostratum e 3. B. scirpeum 
espécimes, embora ocorram alguns indivíduos com caule aéreo reduzido; deste rizoma saem os escapos na região mais apical, as raízes e as folhas na região mais basal. Essa espécie pode apresentar viviparidade nos escapos.

As raízes de $B$. albidum, $B$. prostratum e $B$. scirpeum são cilíndricas e muito finas (Fig. 1-3). Nos diagramas dos cortes transversais das regiões medianas destas raízes, observa-se que o diâmetro do cilindro vascular possui espessura até duas vezes maior quando comparado com o córtex (Fig. 4, 6, 8). Estas raízes são do tipo que possuem células corticais isodiamétricas, dentro das Eriocaulaceae. Em corte transversal, a epiderme (E) é unisseriada de paredes finas e formas irregulares e não há qualquer evidência morfológica de exoderme (Fig. 5, 7, 9). O córtex ( $\mathrm{Cx}$ ) possui apenas duas-três camadas de células com formas irregulares, paredes finas e pequenos espaços intercelulares (Fig. 5, 7, 9). A endoderme (EN) é formada por células de paredes alongadas no sentido periclinal, com paredes espessadas. Em B. albidum, a endoderme possui uma a duas camadas de células (Fig. 5), em B. prostratum, duas a quatro camadas (Fig. 7) e, em B. scirpeum, a endoderme é unisseriada (Fig. 9). O cilindro vascular é delimitado pelo periciclo (P), que se apresenta unisseriado em todas as espécies e com células de paredes fortemente espessadas (Fig. 5, 7, 9). O cilindro vascular apresenta estrutura poliarca com dois elementos de metaxilema (Mx), como em B. albidum (Fig. 5) e B. prostratum (Fig. 7) ou, com um elemento de metaxilema (Mx) como em B. scirpeum (Fig. 9) e, vários pólos de protoxilema (Px) (Fig. 5, 7, 9).

Os diagramas dos cortes transversais do caule aéreo de $B$. albidum nas regiões basal, mediana e apical são observados nas Fig. 10-19. Observam-se duas regiões distintas: o córtex e o cilindro vascular. O periciclo delimita o córtex do cilindro vascular. A endoderme não é evidenciada (Fig. 10-19, 40). Na região basal, a distribuição dos feixes vasculares anfivasais é cilíndrica e periférica (Fig. 10-12) e estão localizados na porção mais interior do periciclo. O córtex é estreito quando comparado ao cilindro central. A medula também é estreita (Fig. 10-12, 40). Observa-se (Fig. 11) a presença da base de uma folha envolvendo o caule. Nas regiões anteriores e posteriores às ramificações do caule (Fig. 1216), ocorre anastomose dos feixes vasculares formando um tecido contínuo; observa-se também nesta região, a saída de raízes adventícias (Fig. 15-16, Ra). Tanto as raízes adventícias ( $\mathrm{Ra}$ ), como os traços foliares (Tf) e os traços dos escapos (Es) se originam a partir do periciclo. Nas regiões apicais do caule (Fig. 17-19) observam-se as saídas de escapos florais (ES), das folhas (F) apicais e uma nova região de ramificação do caule.

Os diagramas dos cortes transversais do caule aéreo de $B$. prostratum nas regiões basal, mediana e apical podem ser observados nas Fig. 20-27 e também apresentam duas regiões distintas: o córtex e o cilindro vascular. Na região basal do caule (Fig. 20-23) observam-se saídas de raízes adventícias (Ra) e de traços foliares (Tf). Os tecidos vasculares da futura raiz situam-se no cilindro, próximos do periciclo (Fig. 23-seta) e são totalmente envolvidos por ele (Fig. 22-Ra) e deslocados para o córtex (Fig. 22-21-Ra). Já no córtex (Fig. 21-Ra), a nova raiz possui seu próprio periciclo e sai para fora do caule (Fig. 20-Ra). Os tecidos vasculares do caule que vão se dirigir para a folha - traços foliares (Tf), também localizam-se bem próximos do periciclo (Fig. 21-seta), são envolvidos por ele e deslocados para o córtex (Fig. 22-Tf), chegando até a folha (Fig. 22-F). O periciclo delimita o córtex do cilindro vascular. A endoderme não é evidenciada. Os feixes vasculares distribuem-se cilindricamente, são anfivasais e situam-se internamente ao periciclo (Fig. 20-23). Na região mediana, local da ramificação (Fig. 24-25), ocorre anastomose dos feixes vasculares, formando um arco. Na região apical (Fig. 26-27) os tecidos vasculares formam novamente um cilindro único após a ramificação e observa-se a saída do traço do escapo (Fig. 26-TEs) do cilindro vascular para o córtex e já fora dele (Fig. 27-Es).

Os diagramas dos cortes transversais do rizoma de $B$. scirpeum nas regiões: basal, mediana e apical podem ser observados nas Fig. 28-33 e também apresentam duas regiões distintas: o córtex e o cilindro vascular. A endoderme não é evidenciada. O periciclo delimita o córtex do cilindro vascular e os tecidos vasculares estão situados internamente ao periciclo (Fig. 28-33). Na região basal (Fig. 28-29), os tecidos vasculares 


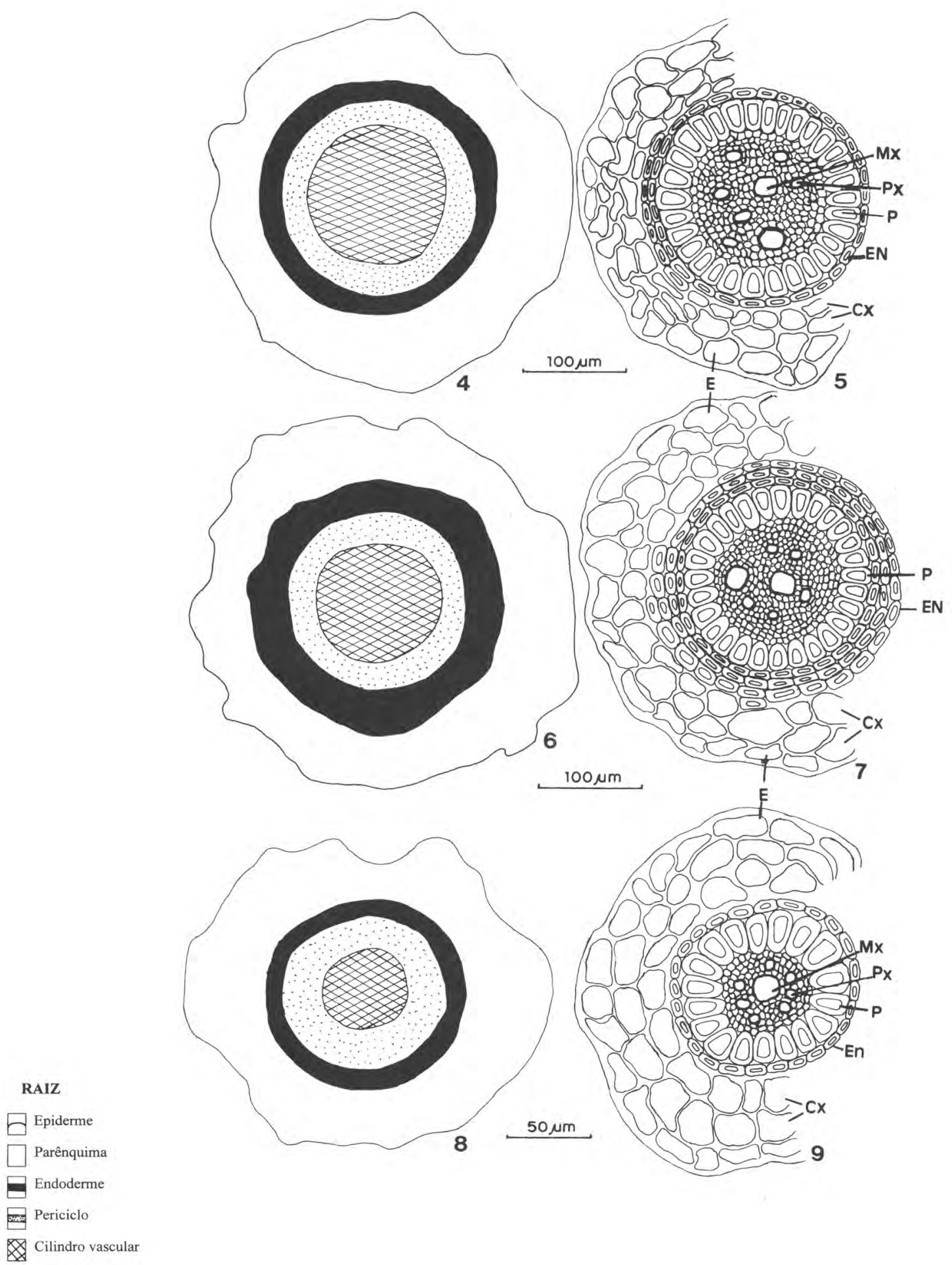

Figuras 4-9. Diagramas e aspectos anatômicos das secções transversais da região mediana das raízes de Blastocaulon: 4-5. B. albidum, 6-7. B. prostratum e 8-9. B. scirpeum (Cx - córtex, E - epiderme, EN - endoderme, Mx - metaxilema, P - periciclo, Px - protoxilema). 

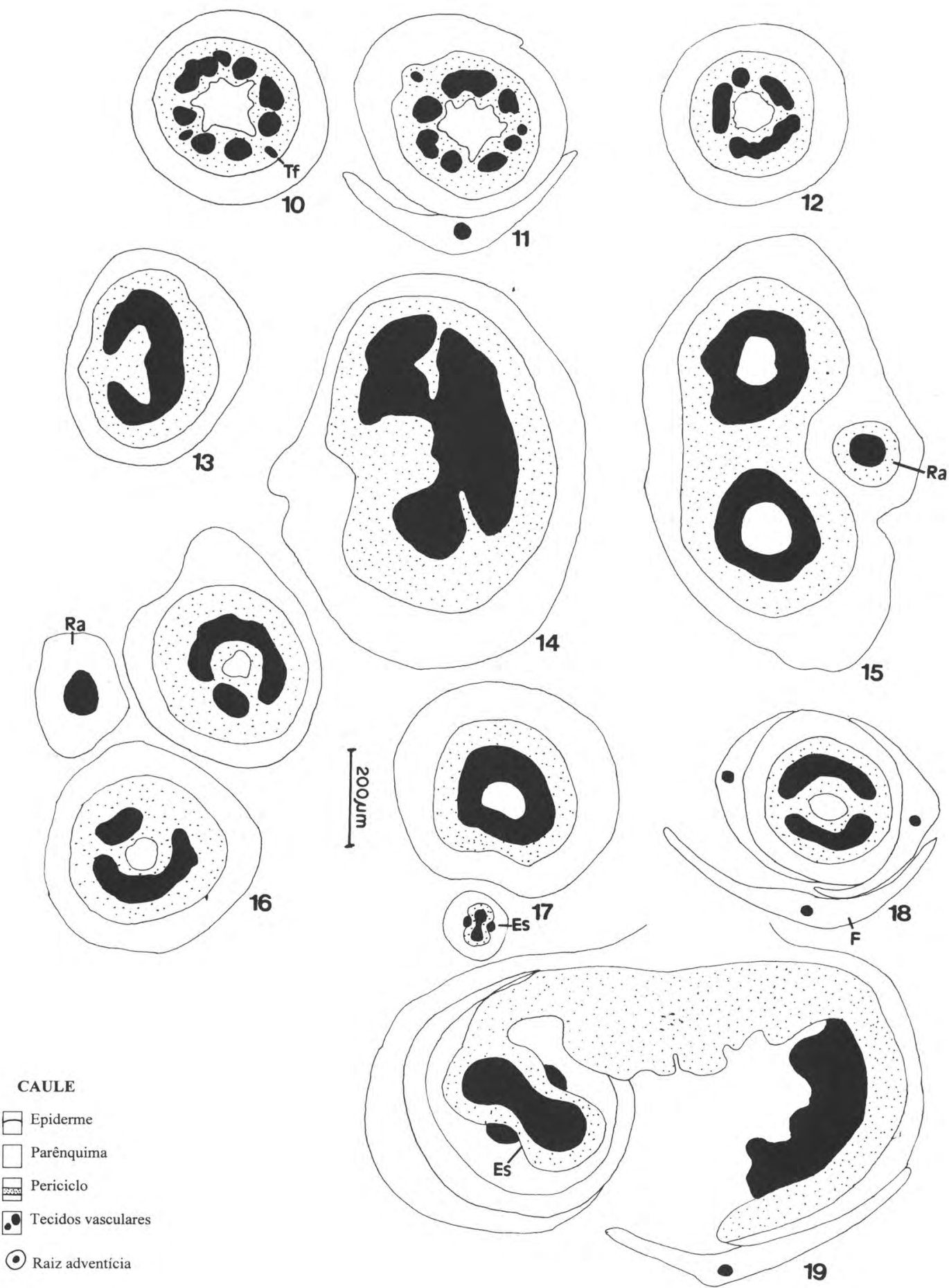

Figuras 10-19. Diagramas das secções transversais do caule de B. albidum nas regiões: 10-12. basal, 13-15. mediana e 166-19. apical (ES - escapo, F - folha, Ra - raiz adventícia, Tf - traço foliar) 

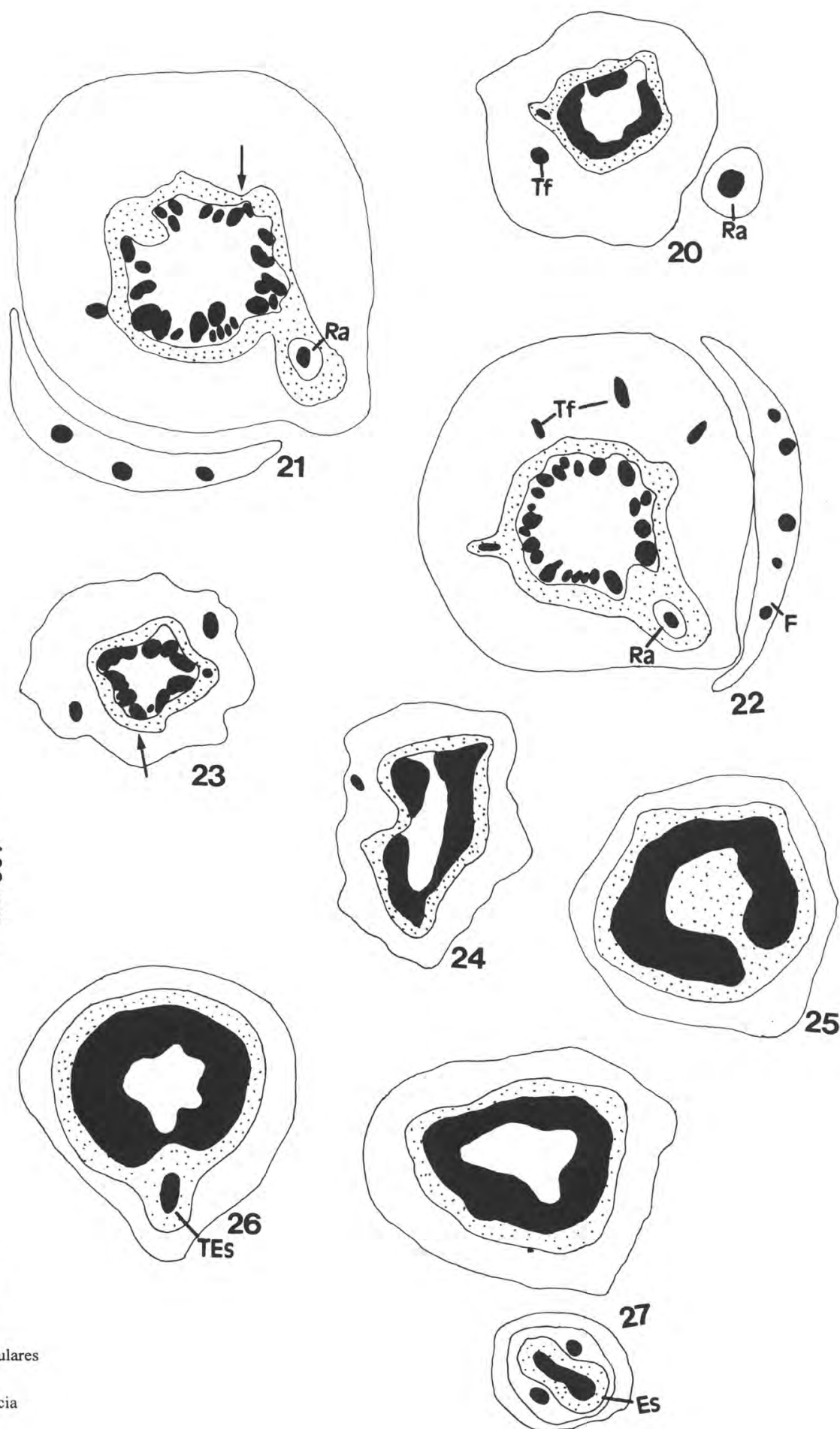

Figuras 20-27. Diagramas das secções transversais do caule de B. prostratum nas regiões: 20-22. basal, 23-25. mediana e 26-27. apical (ES - escapo, F - folha, TEs - traço de escapo, Ra - raiz adventícia, Tf - traço foliar) 
encontram-se anastomosados, formando um cilindro. Ainda na região basal (Fig. 29), pode-se observar a saída de raízes adventícias (Ra). Na região mediana (Fig. 30-31) ocorre também a saída de raízes adventícias $(\mathrm{Ra})$ e de traços foliares (Tf) e, na região apical (Fig. 32-33), na porção mais próxima do ápice, observa-se a saída do escapo (ES) e a proliferação de células do periciclo que vai formar outra ramificação do rizoma (Fig. 33). Também para $B$. scirpeum, tanto a origem de raízes adventícias como dos traços foliares e dos traços dos escapos se dá a partir do periciclo.

Em todas as espécies estudadas, o caule é revestido por células epidérmicas unisseriadas, retangulares, de paredes finas, como pode ser observado em B. albidum (Fig. 40).

Os diagramas dos cortes transversais na região mediana das folhas de B. albidum (Fig. 34), B. prostratum (Fig. 36) e B. scirpeum (Fig. 38) mostram que as lâminas foliares apresentam número variado de feixes vasculares, porém muito reduzidos quando comparadas às de outras espécies de Eriocaulaceae. As folhas de B. albidum (Fig. 34, 42) e B. scirpeum (Fig. 38, 43) apresentam de um a três feixes vasculares, sendo um central - maior e, dois laterais - menores (Fig. 38, 42); em B. prostratum variam de três a oito feixes vasculares (Fig. 36, 41).

O mesofilo das três espécies estudadas é dorsiventral (Fig. 41-43) e quando apresenta mais de um feixe vascular, o parênquima clorofiliano é interrompido pelas extensões de bainha dos feixes vasculares (Fig. 36, 38, 41-42). O parênquima clorofiliano é frouxo (Fig. 41-43), com número reduzido de estômatos e estes estão restritos à face abaxial, como pode ser observado em $B$. prostratum (Fig. 41-ES). A epiderme (E) é unisseriada, de paredes finas, com as células alongadas no sentido longitudinal (Fig. 41-43). Em B. prostratum, na região do bordo, essas células possuem a parede periclinal externa mais espessada que a interna. Os feixes vasculares são colaterais e apresentam bainha dupla: a externa (BE), que é parenquimática e de origem endodérmica, e a interna (BI), que é esclerenquimática e de origem periciclíca (Fig. 34, 36, 38; 41-43). A extensão de bainha dos feixes vasculares nas espécies estudadas são parenquimáticas e estão em contato com as duas faces da epiderme apenas nos feixes maiores (Fig. 36, 38, 41-43).

Os escapos de B. albidum, B. prostratum e $B$. scirpeum são finos, cilíndricos e, em corte transversal, apresentam-se de forma diagramática nas Fig. 35, 37, 39 respectivamente. Nota-se que nos escapos dessas espécies não são formadas as costelas e nem ocorre tecido de sustentação (esclerênquima), comuns à outras Eriocaulaceae. Em todas as espécies estudadas, os escapos são revestidos por epiderme (E) e, entre a epiderme e o cilindro vascular, está o córtex, que é constituído por parênquima e/ou colênquima, mais o parênquima clorofiliano e a endoderme (EN), que é descontínua (Fig. 35, 37, 39, 44). O periciclo (P) envolve totalmente os feixes vasculares menores e parcialmente os maiores. Os feixes vasculares são colaterias e apresentam-se em número de quatro, sendo dois menores e dois maiores, com xilema e floema pouco desenvolvidos (Fig. 35, 37, 39, 44).

\section{Discussão}

As espécies de Blastocaulon aqui estudadas são muito delicadas e ocorrem em locais sombreados e úmidos, margeando cavernas e grutas. Em B. albidum e em B. prostratum ocorrem caule aéreo com entrenós distintos, as folhas distribuemse ao longo do mesmo e os escapos predominam nas porções terminais do caule, enquanto que em $B$. scirpeum predomina o rizoma, como outra forma de crescimento, e as folhas se distribuem em forma de rosetas, sendo que o escapo é terminal. Com relação ao hábito, somente $B$. scirpeum se encaixa no padrão mais freqüente para as Eriocaulaceae e descrito por Giulietti \& Hensold (1990), onde as espécies caracterizamse pelo hábito em roseta, de onde partem os escapos. B. albidum e B. prostratum possuem o hábito diferente das demais Eriocaulaceae estudadas, têm o caule levemente prostrado e folhas glaucas. Nas populações de Minas Gerais, B. prostratum são encontradas formando um tapete na entrada das grutas, ou ao lado de pedras muito grandes. Esses ambientes são muito sombreados e úmidos, formam camada muito fina de solo, mas não ficam alagados. B. scirpeum, por outro lado, é encontrada no interior de rios, presa ao substrato, 

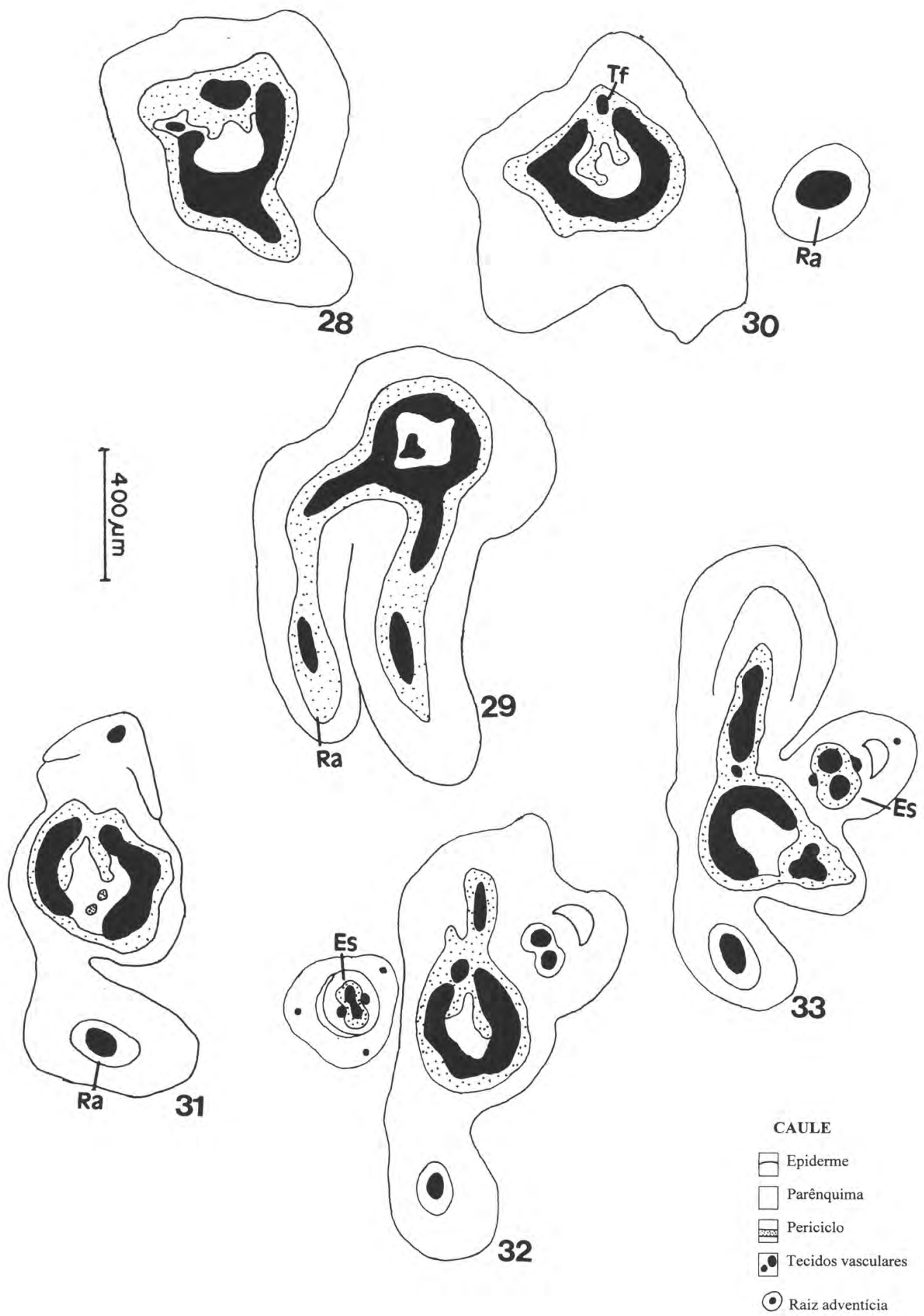

Figuras 28-33. Diagramas das secções transversais do rizoma de B. scirpeum nas regiões: 28-29. basal, 30-31. mediana e 32-33. apical (ES - escapo, Ra - raiz adventícia, Tf - traço foliar) 

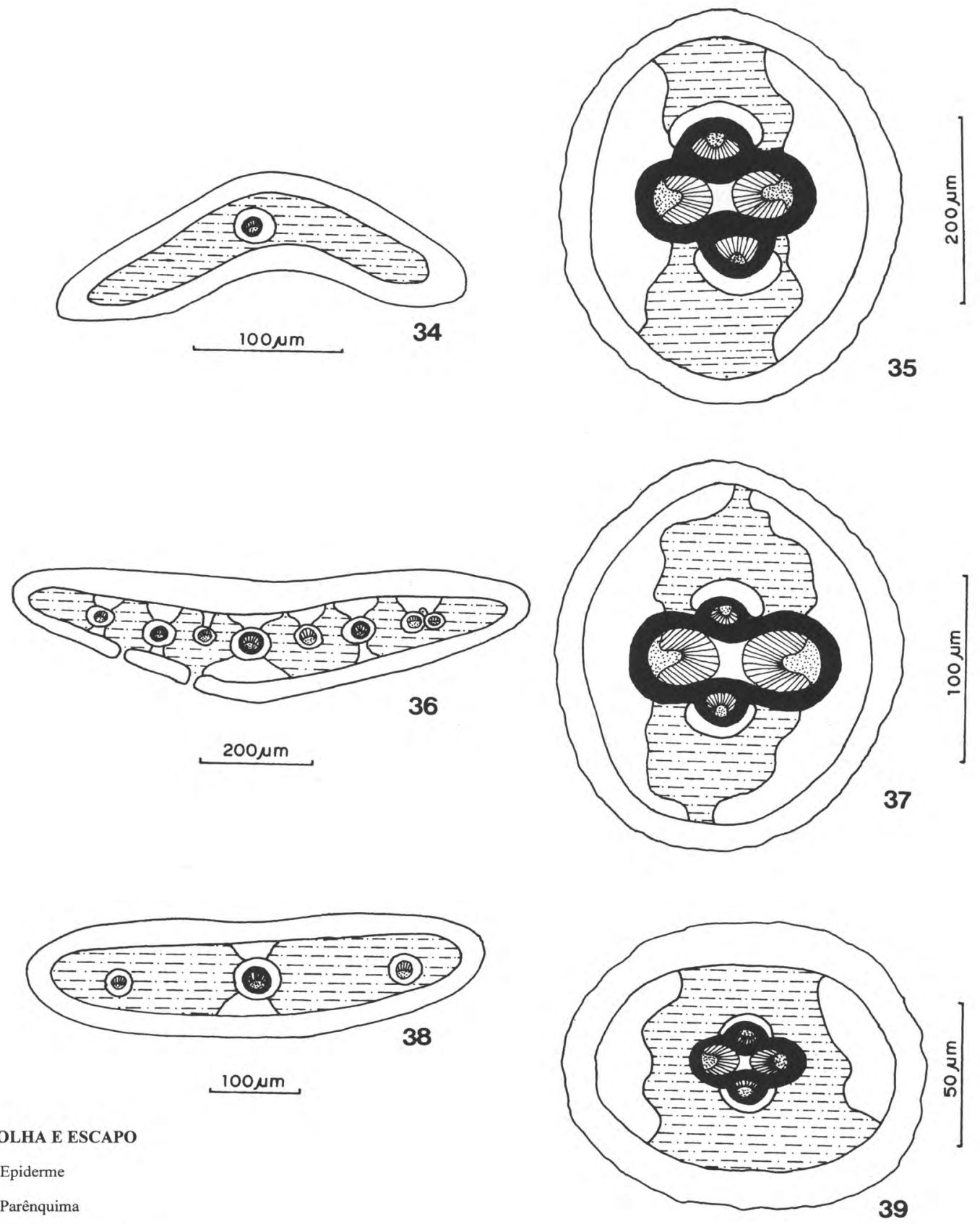

\section{FOLHA E ESCAPO}

\begin{tabular}{|c|c|}
\hline & Epiderme \\
\hline & Parênquima \\
\hline & Parênquima clorofiliano \\
\hline & Endoderme/ bainha externa \\
\hline & Periciclo / bainha interna \\
\hline . & Floema \\
\hline & Xilema \\
\hline
\end{tabular}

Figuras 34-39. Diagramas das secções transversais da região mediana das folhas e dos escapos de Blastocaulon: B. albidum 34. folha, 35. escapo. B. prostratum 36. folha, 37. escapo. B. scirpeum 38. folha, 39. escapo 


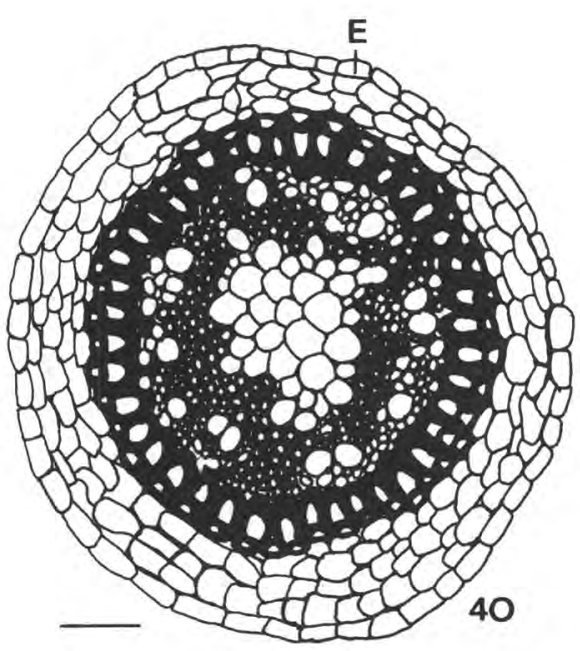

E

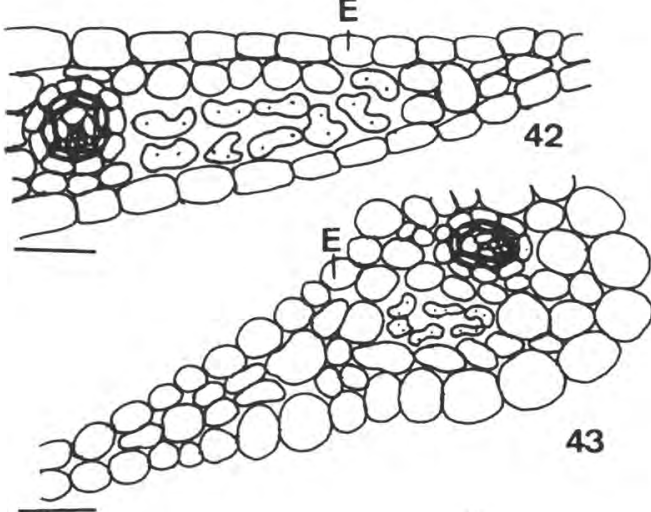

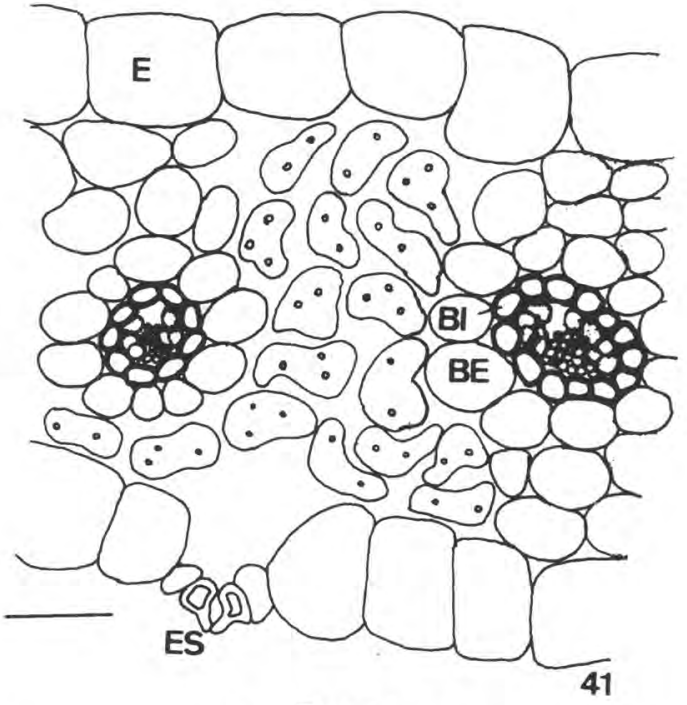

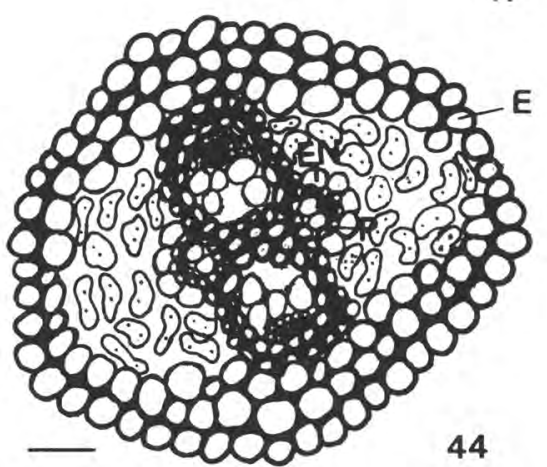

44

Figuras 40-44. Aspectos anatômicos das secções transversais da região mediana de: 40 . caule de $B$. albidum $($ Barra $=50 \mu m)$; folhas de: 41. B. prostratum $($ Barra $=20 \mu \mathrm{m}), 42$. B. albidum $($ Barra $=30 \mu \mathrm{m})$ e 43. B. scirpeum $(B a r r a=50 \mu \mathrm{m}) ; 44$. escapo de B. prostratum $(\mathrm{Barra}=30 \mu \mathrm{m})(\mathrm{BE}$ - bainha externa, BI - bainha interna, E - epiderme, EN - endoderme, ES - estômato, $\mathrm{P}$ - periciclo $)$

porém não exposta ao sol. Essas espécies diferem de outras Eriocaulaceae já estudadas, que crescem em ambientes secos, úmidos, até alagados, mas sempre expostas ao sol.

As raízes das espécies de Blastocaulon estudadas são muito finas e delicadas e sua estrutura anatômica se encaixa no tipo uniforme, sem diafragmas corticais, descritos por Malmanche (1919) e por Tomlinson (1969) para as espécies terrestres de Eriocaulaceae. São semelhantes com espécies do gênero Syngonanthus como $S$. imbricatus, $S$. aurifibratus e $S$. elegans estudadas por Scatena \& Menezes (1996b); com espécies de Paepalanthus, como $P$. vellozioides, $P$. latipes e $P$. pauciflorus estudadas por Scatena \& Moraes (1996) e P. hilairei estudada por Scatena \& Barros (1996), em que as raízes são relativamente finas e as células do parênquima cortical são todas isodiamétricas, sem grandes espaços intercelulares. Todas estas espécies vivem em solos secos e não possuem parênquima cortical com reserva de ar.

A estrutura anatômica das raízes de Blastocaulon tambémé semelhante à estrutura anatômica das raízes de Tonina fluviatilis (Scatena \& Giulietti - dados inéditos) que se distribuem ao longo do caule e são muito finas. Possuem córtex reduzido a uma ou duas camadas de células, e os tecidos vasculares do cilindro também são reduzidos. 
Em relação aos caules aéreos de $B$. albidum e $B$. prostratum, estes são semelhantes na morfologia e na estrutura anatômica aos de Syngonanthus com caules aéreos (Scatena \& Menezes 1995). A diferença é que, enquanto nas espécies de Syngonanthus a endoderme é evidente, o mesmo não ocorre em Blastocaulon. O rizoma de B. scirpeum é semelhante na morfologia e na estrutura anatômica aos rizomas das espécies de Syngonanthus, que possuem rizomas curtos (Scatena \& Menezes 1995).

A origem de raízes adventícias, de traços foliares e de traços dos escapos a partir do periciclo nas espécies de Blastocaulon estudadas são semelhantes ao que já foi descrito para outras espécies de Eriocaulaceae, principalmente para várias espécies de Syngonanthus (Scatena \& Menezes 1996b) e para Leiotrix crassifolia (Scatena \& Rocha 1995).

As folhas de todas as espécies de Blastocaulon estudadas diferem de outras Eriocaulaceae já estudadas, como as dos gêneros Leiothrix (Scatena \& Giulietti 1996; Monteiro et al. 1985), Syngonanthus (Scatena \& Menezes 1996a) e Paepalanthus (Castro \& Menezes 1995; Scatena \& Barros 1996; Scatena \& Moraes 1996) pelo tamanho reduzido, textura muito delicada, células da epiderme com paredes finas, parênquima clorofiliano frouxo e número reduzido de feixes vasculares; enquanto que as espécies dos outros gêneros apresentam as células da epiderme totalmente espessadas, ou com espessamento diferencial, parênquima clorofiliano compacto na maioria das espécies, e vascularização intensa. A grande maioria dessas folhas revelam características xerofíticas em diferentes graus.

As estruturas anatômicas das folhas de Blastocaulon assemelham-se mais com as encontradas nas folhas de espécies aquáticas de Eriocaulon, como E. aquatile, E. cipoense, E. crassiscapum, E. elichrysoides e E. melanocephalum (Monteiro et al. 1984), que apresentam cutinização pobre, paredes das células epidérmicas finas, reduzido número de feixes vasculares na maioria das espécies e xilema pouco desenvolvido.
Em relação aos escapos, as espécies de Blastocaulon estudadas possuem estrutura anatômica bastante diferente das demais espécies de diferentes gêneros de Eriocaulaceae já estudadas, como Syngonanthus (Malmanche 1919; Scatena \& Menezes 1996a), Leiothrix (Giulietti 1978b; 1984; Scatena \& Rocha 1995; Scatena \& Giulietti 1996), Eriocaulon (Malmanche 1919; Giulietti 1978b) e Paepalanthus (Malmanche 1919; Castro 1986; Scatena \& Barros 1996; Scatena \& Moraes 1996). Essas diferenças consistem, principalmente, na ausência de costelas, nas células epidérmicas com paredes finas, na ausência de tecidos de sustentação (esclerênquima) no parênquima cortical, na redução do número de feixes vasculares e na redução do xilema e do floema.

As espécies de Blastocaulon podem ser caracterizadas por apresentar raízes muito finas, epiderme unisseriada, sem evidência de exoderme, parênquima cortical reduzido (duas-três camadas), tecidos vasculares com poucos elementos; caules aéreos, prostrados, ramificados em $B$. albidum e B. prostratum, rizoma ou caule muito curto em B. scirpeum, todos eles com: epiderme, córtex e cilindro vascular com feixes anfi-vasais. Tanto as raízes adventícias, como os traços foliares e os traços dos escapos originamse a partir do periciclo. As folhas são pequenas e delicadas, as células da epiderme, com paredes finas, possuem parênquima clorofiliano frouxo e reduzido número de feixes vasculares colaterais. Os escapos são cilíndricos, finos, sem costelas, com apenas quatro feixes vasculares colaterais. Todas essas características são típicas de plantas que ocorrem em locais úmidos e sombreados, ambientes onde são encontradas as espécies estudadas.

As características anatômicas de todos os órgãos de B. scirpeum estudados neste trabalho mostram que essa espécie está bem localizada dentro do gênero. Essa informação confirma a validade de transferência de Paepalanthus scirpeus para o gênero Blastocaulon, conforme proposto por Giulietti (1978a), que se baseou apenas nas anteras monotecas. 


\section{Referências bibliográficas}

Castro. N. M. 1986. Estudos morfológicos dos órgãos vegetativos de espécies de Paepalanthus Kunth (Eriocaulaceae) da Serra do Cipó (Minas Gerais). Dissertação de Mestrado. USP, São Paulo.

Castro. N. M. \& Menezes, N. L. 1995. Aspectos da anatomia foliar de algumas espécies de Paepalanthus Kunth. Eriocaulaceae da Serra do Cipó (Minas Gerais). Acta Botanica Brasilica 9(2): 213-229.

Giulietti, A. M. 1978a. Blastocaulon scirpetum (Mart.) Giul., uma nova combinação para Paepalanthus scirpeus Mart. Boletim de Botânica da Universidade de São Paulo 6: 61-65.

Giulietti. A. M. 1978b. Os gêneros Eriocaulon L. e Leiothrix Ruhl. (Eriocaulaceae) na Serra do Cipó, Minas Gerais, Brasil. Tese de Doutorado. USP, São Paulo.

Giulietti. A. M., 1984. Estudos taxonômicos no gênero Leiothrix Ruhl. (Eriocaulaceae). Tese de Livre Docência. USP, São Paulo.

Giulietti. A. M. \& Hensold, N. 1990. Padrões de distribuição geográfica dos gêneros de Eriocaulaceae. Acta Botanica Brasilica 4(I): 133-159.

Giulietti. A. M.. Amaral, M. C. E. \& Bittrich, V. 1995. Phylogenetic analysis of inter-and infrageneric relationships of Leiothrix Ruhland (Eriocaulaceae). Kew Bulletin 50(1): 55-71.

Malmanche, L. A. 1919. Contribution à l'étude anatomique des Eriocaulonacées et des familles voisines. Restiacées, Centrolepidacées, Xyridacées, Philhydracées, Mayacacées. Thesis. St. Cloud, Paris.

Monteiro. W. R: Giulietti, A. M. \& Castro, M. M. 1984. Aspects of leaf structure of some species of Eriocaulon L. (Eriocaulaceae) from the Serra do Cipó (Minas Gerais, Brazil). Revista Brasileira de Botânica 7(2): 137-147.

Monteiro, W. R., Castro, M. M. \& Giulietti, A. M. 1985. Aspects of leaf structure of some species of Leiothrix Ruhland (Eriocaulaceae) from the Serra do Cipó (Minas Gerais, Brazil), Revista Brasileira de Botânica 8(1): 109-125.
Roeser. K. R. 1962. Die Nadel der SchwarzkieferMassenprodukt und Kunstwert der Natur. Mikrokosmos 61: 33-36.

Ruhland. W. 1903. Eriocaulaceae. In: A. Engler (Ed.), Das Pflanzenreich. IV. 30: 1-294. Wilhelm Engelmann. Leipzig.

Scatena. V. L. \& Menezes, N. L. 1995. Aspectos morfológicos e anatômicos do caule em espécies de Syngonanthus Ruhl. Eriocaulaceae. Boletim de Botânica da Universidade de São Paulo 14: 91-107.

Scatena. V. L. \& Rocha, C. L. M. 1995. Anatomia dos órgãos vegetativos e do escapo floral de Leiothrix crassifolia (Bong.) Ruhland, Eriocaulaceae, da Serra do Cipó-MG. Acta Botanica Brasilica 9(2): 195-211.

Scatena. V. L. \& Barros, A. M. 1996. Aspectos morfoanatômicos de Paepalanthus hilairei Koern. (Eriocaulaceae) da Serra do Cipó-MG. Arquivos de Biologia e Tecnologia 39(1): 75-88.

Scatena. V. L. \& Giulietti, A. M. 1996. The taxonomy and morphological and anatomical differentiation of populations of Leiothrix crassifolia (Eriocaulaceae). Plant Systematic and Evolution 199: 243-258.

Scatena, V. L. \& Menezes, N. L. 1996a. Anatomia de escapos e folhas de Syngonanthus Ruhl. (Eriocaulaceae) de campos rupestres. Revista Brasileira de Biologia 56(2): $317-332$.

Scatena. V. L. \& Menezes, N. L. 1996b. Anatomia de raízes de Syngonanthus Ruhl. (Eriocaulaceae). Revista Brasileira de Biologia 56(2): 333-343.

Scatena. V. L. \& Moraes, A. R. S. 1996. Anatomia de raízes, folhas e escapos de Paepalanthus subgênero Platycaulon (Eriocaulaceae) da Serra do Cipó-MG. Arquivos de Biologia e Tecnologia 56(2): 317-332.

Scatena. V. L.: Cardoso, V. A. \& Giulietti, A. M. 1998. Anatomia do escapo floral de espécies brasileiras de Paepalanthus subgênero Platycaulon (Eriocaulaceae). Acta Botanica Brasilica 12(3): 121-133.

Tomlinson. P. B. 1969. Commelinales-Zingiberales. In: Metcalfe. C.R. Anatomy of the Monocotyledons. Clarendon Press, v.3, Oxford. 